\title{
The Effect of Delaying Motherhood on the Second Childbirth in Europe ${ }^{1}$
}

\author{
Massimiliano Bratti \\ DEAS, Università degli Studi di Milano \\ Via Conservatorio 7 \\ I-20122, Milan, Italy
}

\author{
Konstantinos Tatsiramos \\ Institute for the Study of Labor (IZA) \\ Schaumburg-Lippe-Strasse 5-9 \\ 53113, Bonn, Germany \\ Email: tatsiramos@iza.org
}

September 21, 2010

\begin{abstract}
We examine the effect of delaying motherhood on the transition to the second childbirth across European countries. There exist two opposite forces of delaying the first birth: biological and socio-cultural factors producing a postponement effect and career-related factors leading to a catch-up effect. Estimating a multistate duration model that addresses the endogeneity of age at first birth, we find a catch-up effect in countries where the career-effect is large and a postponement effect in countries where the opportunity cost of childbearing is relatively high due to the lack of family friendly institutions and cultural influences, which may discourage late childbearing.
\end{abstract}

JEL: C41; J13

Keywords: fertility, postponement, duration

\footnotetext{
${ }^{1}$ Corresponding author: Konstantinos Tatsiramos.

Acknowledgements. We thank three anonymous referees, Deborah Cobb-Clark, John Ermisch and Daniel Hamermesh for their very helpful comments and discussions. Earlier versions of this paper (circulated under the title "Explaining How Delayed Motherhood Affects Fertility Dynamics in Europe", IZA DP No 3907) have also benefited from comments received at seminars at IZA, RWI-Essen, MPI in Rostock and Keele University, the BHPS Conference in Colchester, the III Workshop on 'Economics of the Family' in Zaragoza, the ESPE Conference in London, the EALE Conference in Amsterdam and the EEA Conference in Barcelona. The paper is partly based on work carried out by Massimiliano Bratti during his visits to the European Centre for Analysis in the Social Sciences (ECASS) at the Institute for Social and Economic Research (University of Essex) supported by the Access to Research Infrastructure action under the European Community's 'Improving Human Potential Programme', and at IZA in Bonn, which are both acknowledged for their financial assistance. The usual disclaimer applies.
} 


\section{Introduction}

Two well known empirical facts regarding fertility in developed countries are the decline in Total Fertility Rates (TFRs), which are now below the so-called "replacement level" of 2.1 children per woman, and the increase in a woman's age at first birth. The negative correlation observed between a woman's age at first birth and total fertility suggests that delaying motherhood may be an important determinant of the fertility decline (postponement effect). Understanding, therefore, these "tempo-quantum interactions" or tempo effects (Kohler et al., 2002) is important for policies aiming to address population aging and its negative economic consequences. Indeed, in the presence of a causal effect of age at first birth on subsequent fertility, policy makers may change fertility dynamics by affecting this age (Lutz and Skirbekk, 2005).

This paper contributes to the debate on the effect of delaying motherhood on fertility dynamics in three ways. First, we seek to provide micro-level evidence on the effect of age at first birth on the transition to the second parity. Estimating a multistate discrete-time duration model, which accounts for correlated unobserved heterogeneity across parities, we are able to address the endogeneity of age at first birth. Endogeneity may arise because some unobserved variables, such as preferences towards having children or fecundability, may simultaneously affect both fertility tempo and fertility quantum and generate a spurious correlation between the two. ${ }^{2}$ Second, unlike previous work mainly featuring individual country studies, we investigate the consequences of delaying motherhood on fertility in several European countries using highly standardized

\footnotetext{
${ }^{2}$ Our focus on the first two parities is motivated by the observed decline in the TFR below two children per woman, which makes the transition to the second birth the relevant margin to study. Moreover, despite the declining trend in TFRs, survey data usually show that the modal desired number of children per woman is still two, and that many women fail even this relatively low fertility target (Bongaarts, 2001).
} 
individual-level data from the European Community Household Panel (ECHP). This enables us to analyze the pace of tempo effects separately in each country and to relate potential differences in these effects to countries' specific institutional characteristics. ${ }^{3}$ Third, we consider the interplay between female labor force attachment and fertility decisions. ${ }^{4}$ In particular, we provide an explanation as to why the effect of delaying the first birth on the transition to the second parity is likely to differ between career and noncareer oriented women. In this way, we aim to extend the arguments posited by the existing literature on the "career-planning motive" for delaying the first birth, by assessing its implications for the transitions to higher child parities. Distinguishing between career and non-career oriented women also helps us to reconcile the contrasting evidence on tempo effects coming from previous studies that do not make such a distinction. $^{5}$

The empirical analysis shows that two opposite forces - biological and sociocultural factors producing a postponement effect and career-related factors leading to a catch-up effect - co-exist and have different magnitudes depending on countries' institutional features determining the overall sign of tempo effects. In particular, the postponement effect is larger in Southern European countries, where a traditional view on the role of women prevails and where it is generally difficult to reconcile family and work, while a catch-up effect is sizeable in countries where institutions - child-care and part-time jobs availability, longer maternal leaves and higher wages - make it easier for mothers to participate in the labor market.

\footnotetext{
${ }^{3}$ Our work is also related to cross-country studies that observe a reversal of the negative correlation between female employment and fertility (Ahn and Mira, 2002).

${ }^{4}$ As it is well known, female life-cycle labor force participation and fertility decisions are closely related (see, for instance, Moffit, 1984; Hotz and Miller, 1988; Francesconi, 2002).

${ }^{5}$ For instance, Heckman et al. (1985) and Heckman and Walker (1990) show the existence of a catch-up effect in Sweden, while Kohler et al. (2002) find a strong postponement effect in Southern European countries.
} 
The structure of the paper is the following. The next section introduces a simple analytical framework which suggests the existence of differential tempo effects according to women's work attachment and countries' institutions. Section 3 introduces the ECHP data and reports some sample descriptive statistics, and Section 4 describes the multistate discrete-time duration model used in the empirical analysis. In Section 5, we report and discuss our main findings concerning the effect of the age at first birth on the timing of the second childbirth. Section 6 concludes.

\section{An analytical framework for tempo effects}

In this section, we set a simple analytical framework which helps us to motivate our empirical strategy and to interpret the results. We distinguish the overall effect of delaying motherhood (tempo effects) into three causal pathways. The first two (the biological effect and the socio-cultural effect) operate on all women irrespective of labor force attachment, while the third one (the career effect) operates only on working women. These pathways are likely to produce either a postponement effect, i.e. a negative effect of age at first birth on the hazard of progressing to the following parities, or a catch-up effect, i.e. a positive effect on higher parity progression. In the following, we discuss each of these channels and the extent to which they might differ across countries.

The biological effect. A reason why women who delay the birth of their first child might be slower in achieving the following parities, and even have a lower total fertility, is that their fecundability declines with age. Several studies have shown that women who delay childbearing after the age of 30 are at greater risk of remaining childless due to declining fecundability (see Billari et al. 2007, for a review). This causal pathway from 
age at first birth to fertility produces a postponement effect. The effect of aging on the biological decline of fecundability could be mitigated by means of assisted reproductive technologies (ART), which are not equally available or used in all countries (see Langdridge and Blyth, 2001). For this reason, the biological effect may have a different impact across countries and be more severe in those with stricter ART regulation.

The socio-cultural effect. As stressed by Billari et al. (2007), limits to the delay of childbearing are not only of a biological but also of a cultural or social nature. ${ }^{6}$ In several countries, people perceive a normative "age deadline" for childbearing. In both Italy and France, for instance, this age is reported to be around 40 . Women who had their first child relatively late may refrain from having additional children when they approach their 40s because of the perception of being too old to become mothers again. This causal pathway from age at first birth to fertility would produce a postponement effect: those mothers who had their first child late are less likely to progress to the second parity. ${ }^{7}$ As with the biological effect, this socio-cultural effect is likely to be country-specific given the different social and cultural environments of European countries. We expect social or cultural norms against very late fertility to be stronger in Southern European countries in which mothers are traditionally given a primary role in childrearing and where female labor force participation and external childcare are still relatively low ("male breadwinner model").

The career effect. Dynamic models of fertility have shown that there are two main motives for delaying fertility: "consumption smoothing" and "career planning" (see, for

\footnotetext{
${ }^{6}$ Culture has recently been shown to be important in shaping women's fertility and labor force participation decisions (see for instance, Fernandez and Fogli, 2006, 2009).

7 To avoid potential confusion, these social influences could push women to have their first birth earlier. This is something completely different from the postponement effect, which posits that women who have their first birth later are less likely to proceed to the second parity.
} 
instance, Cigno and Ermisch, 1989; Blackburn et al., 1993; Walker, 1995; Gustafsson, 2001). The consumption smoothing argument posits that, in the presence of capital market imperfections, women have children when their incomes are high enough to bear the costs of childrearing and to smooth consumption inter-temporally. The career planning motive posits that working women give birth when it penalizes their careers less, which means when they have accumulated substantial work experience. Hence, we should observe a negative effect of women's labor force attachment on the hazard of the first birth. The effect of delaying motherhood due to the career planning motive on fertility quantum is, however, theoretically ambiguous (Cigno and Ermisch, 1989). On the one hand, given that the age-profile of wages is positive and steeper at younger ages, delaying motherhood may produce an increase in women's wages and lifetime earnings and raise the demand for children of working women (Ahn and Mira, 2002; Apps and Rees, 2004; Martínez and Iza, 2004). On the other hand, higher women's wages have not only a positive income effect but also a negative substitution effect on the demand for children. However, the latter is likely to be lower the higher the possibility of reconciling family and work, that is of giving birth without having to withdraw from the labor market. Therefore, the effect of delaying motherhood on higher parity progression is likely to vary both in sign and magnitude across countries depending on the price of children. ${ }^{8}$

In particular, the opportunity cost of childbearing and the price of children are

\footnotetext{
${ }^{8}$ Theoretically, there is no reason why the income effect should prevail over the substitution effect. Empirically, evidence that late motherhood is positively associated with mothers' wages can be found in Amuedo-Dorantes and Kimmel (2005) and Miller (forthcoming), while Davies and Pierre (2005) use ECHP data to show that mothers under 24 are more likely to suffer from a family wage gap than older mothers. Del Bono et al. (2008) show that an unexpected career interruption, which lowers the opportunity cost of giving birth for working mothers, has a sizeable negative effect on women's fertility. This effect could be explained by a reduction in expected life-time earnings due to the destruction of working mothers' firm-specific human capital, which leads to a reduction in permanent income.
} 
relatively low in countries where both low-cost external childcare and part-time opportunities are widely available. Therefore, the income effect may prevail over the substitution effect and the career effect is likely to be positive and large in magnitude. In these countries, mothers in full-time employment can use external childcare without reducing their working hours, or they can temporarily switch to part-time employment around childbirth without penalizing their careers. In contrast, in countries with little public childcare and few part-time employment opportunities, the price of childbearing for working women is high, and an increase in lifetime resources due to delayed motherhood is unlikely to have strong positive effects on their fertility. In these countries, working is incompatible with having many children (Del Boca and Sauer, 2009). Table 1 shows a high coverage of childcare and availability of part-time employment opportunities in countries such as Denmark and France; whilst Southern European countries (Italy, Greece, Portugal and Spain) are characterized by both little access to childcare and a low share of part-time employment. Hence, we expect a higher positive career effect in the former group of countries.

The discussion above suggests some guidelines for our empirical analysis. First, the average effect of delaying the first birth on progression to the second parity is likely to differ between career and non-career oriented women. Hence, unlike previous literature, we will include interaction effects between women's age at first birth and proxies of labor force attachment. Second, the sign and the overall magnitude of tempo effects are likely to depend on the specific institutional and cultural features of each 
country. Thus, separate analysis for each country is performed. ${ }^{9}$

\section{Data}

The analysis is based on individual data from the ECHP (1994-2001). The ECHP is a survey based on a standardized questionnaire that involves annual interviewing of a representative panel of households and individuals in each country, covering a wide range of topics including demographics, employment characteristics, education, etc. In the first wave, a sample of some 60,500 nationally representative households from 12 Member States - approximately 130,000 adults aged 16 and over - were interviewed. The features that make the ECHP relevant for this study are the standardized methodology and procedures yielding comparable information across countries and the longitudinal design in which information on the same set of households and persons is gathered.

In this study we focus on 10 countries (Belgium, Denmark, France, Germany, Greece, Ireland, Italy, Portugal, Spain and the United Kingdom), which have participated since the beginning of the survey, excluding Luxembourg because of its small sample size and the Netherlands due to missing relevant information. The sample consists of all women between 28 and 37 years old at the first observed wave between 1994 and 2001. We construct the age of the mother at each birth using the age of the children in the household. We consider births which have occurred before the first wave in which each woman is observed in the ECHP but also any birth that occurs within the sampling period. We define the duration until first birth as the time elapsed since age 17 until the

\footnotetext{
${ }^{9}$ Estimation of country-specific regressions, which do not impose equality of coefficients across countries, is frequent in the literature using the ECHP, see Nicoletti and Tanturri (2008), Del Boca and Sauer (2009), and Del Boca et al. (2009), among others. However, we also provide evidence based on a pooled cross-country sample in Section 5.6, which allows for interactions between age at first birth and country specific institutional features.
} 
age at the birth of the first child. Women who never give birth are considered as rightcensored observations. For those who give birth to the first child, we can construct the duration to the second childbirth. The sample selection on women's age is made mainly for two reasons. First, we want women to be close to the end of their fecund time-span at the last observed wave (Heckman et al., 1985). Second, we want to select women who are not too old to avoid the risk that they will appear childless because their children have already left the parental home. Table A1 in the Appendix provides summary statistics of the sample.

Table 1 shows the share of women who are childless by age. On average about $16 \%$ of women remain childless at age 35 , which declines to about $12.5 \%$ at age 39 and above. Table 1 also shows that countries with a lower share of childless women have a higher share of women with more than one child. For instance, Belgium, Greece and Ireland, which have among the lowest shares of women without children, also have among the highest shares of women with more than one child. We also present in Table 1 the mean age at first birth for women above 35 at the last observed wave, who are close to completing their fecund life-span. Greece and Portugal exhibit the lowest means of age at motherhood (24.1 and 23.9, respectively).

\section{(Insert table 1 here)}

\section{Econometric framework}

Several studies have found a negative correlation between age at first birth and fertility (Morgan and Rindfuss, 1999, Kohler et al. 2002 among others). However, these studies do not address the issue of potential endogeneity of the first birth with progression to 
higher parities. Endogeneity may arise because some unobserved variables, such as preferences towards children or fecundability, may simultaneously affect both fertility tempo and fertility quantum and generate a spurious correlation between the two. Without taking into account these unobserved effects it is not possible to distinguish a true causal effect from a simple spurious correlation. To the best of our knowledge, only a few studies have tried to tackle the issue of endogeneity. Heckman et al. (1985) and Heckman and Walker (1990) studied tempo effects in Sweden using a multistate transition model and found a catch-up effect. ${ }^{10}$ Kohler et al. (2001) addressed the endogeneity issue using a sibling-estimator and found a postponement effect for Denmark. We contribute to these single country studies by seeking to estimate the causal effect of fertility tempo in several countries, which strongly differ in terms of both culture and institutions.

The statistical analysis is based on a multistate discrete-time duration model, in which both the transition to the first birth and the transition to the second birth, conditional on the age at first birth, are modeled. Following Heckman et al. (1985) and Heckman and Walker (1990) we distinguish the true causal effect of the age at first birth on the transition to the second parity from the spurious correlation due to individual unobserved heterogeneity, that is, to unobserved characteristics which simultaneously determine both the age at first birth and the occurrence of a second birth. ${ }^{11}$ This approach requires modeling the first and second birth simultaneously. A "piecemeal approach" (Heckman et al., 1985), which models each transition in isolation, ignores the presence of unobservables and can produce inconsistent estimates. The methodological approach that

\footnotetext{
${ }^{10}$ The model we estimate is similar to that of Heckman and Walker (1990). The only difference is that we consider only the first two births, while Heckman and Walker (1990) consider also the third birth for Swedish women born before 1950 .

${ }^{11}$ The use of bivariate duration models based on the proportional hazard assumption is common in the analysis of labor market dynamics (see Lancaster, 1990 and van den Berg, 2001 for an overview), but it has also been used extensively in health economics in the analysis of the use of alcohol and tobacco (van Ours, 2004) or drugs (van Ours, 2003).
} 
we adopt has the advantage that by modeling the structure of the decision process (first and second birth) we can identify the effect of interest by integrating out unobserved heterogeneity. To achieve this, we specify a semiparametric model in which we make no assumptions on the distribution of unobserved heterogeneity (discrete distribution) and we allow for flexible piecewise constant duration dependence. Identification requires that after controlling for individual observables any remaining individual unobserved heterogeneity (e.g, woman's fecundability or idiosyncratic tastes for children) is time invariant and uncorrelated with the observed characteristics. An alternative approach which has been followed in the literature relies on using instrumental variables (IV). This requires finding instruments for the age at first birth (e.g. Miller, forthcoming). ${ }^{12}$ In general, the major differences between the two approaches are (i) that the IV estimates critically rely on the validity (exogeneity and strength) of the instruments, while our model is identified without the need of exclusion restrictions but with a random effect assumption $^{13}$, and (ii) in case of heterogeneous treatments IV estimates only recover the local average treatment effect, which is the effect on the individuals whose treatment status is changed by the instrument (compliers). This can be a very limited and not necessarily interesting subpopulation, while with the full information maximum likelihood approach that we follow one can estimate an average treatment effect.

\footnotetext{
${ }^{12}$ Miller (forthcoming) in her study of age at motherhood on career path uses biological fertility shocks as instruments, in particular an indicator for first pregnancy ending in miscarriage or stillbirth, an indicator for "accidental" first pregnancy occurring while using contraception, and the lag in years from first attempt to conceive to first birth. Unfortunately, these variables are not available in the ECHP.

${ }^{13}$ See the discussion on identification at the end of this section. Although we assume that the random effects are orthogonal with respect to the covariates in the model, the model allows for correlation between the unobserved effect and the main variable of interest (age at first birth).
} 


\subsection{The model}

The hazard function, which is defined as the probability that a spell is completed at time $t$ given that it has not been completed before $t$, as a function of $t$, is the basic building block of the discrete-time duration model. In the present context, we define the duration until the first birth $\left(T_{1}\right)$ as the time in years elapsed since age 17 and the duration until the second birth $\left(T_{2}\right)$ as the elapsed time in years since the time of the first birth.

The hazard function for an individual $i$ in state $j=1,2$, which indicates the two transition states, is defined as

$$
\lambda_{j i}\left(t_{j i} \mid y_{j i}\right)=P\left[T_{j i}=t_{j i} \mid T_{j i} \geq t_{j i}, y_{j i}\right]=F\left(y_{j i}\right)
$$

where $F(\cdot)$ denotes the logistic cumulative distribution function. For the transition to the first birth, where $j=1$, the index $y_{j}$ (abstracting from the subscript $i$ ) is defined as

$$
y_{1}=\beta_{01}+\beta_{11} \mathbf{X}_{1}+\sum_{k=1}^{K} \beta_{21} I_{k}\left(t_{1}\right)+\varepsilon_{1}
$$

where the vector $\mathbf{X}_{1}$ includes both time-invariant and time-variant individual characteristics. The effect of duration dependence is modeled by using the yearly time dummies $I_{k}\left(t_{1}\right)$, where $t_{1}$ denotes realizations of the stochastic duration of the spell since age 17 until the first birth, and $k=(1, \ldots, K)$ refers to the year intervals since age 17 .

Similarly for the transition to the second birth, where $j=2$, the index $y_{j}$ is defined as

$$
y_{2}=\beta_{02}+\beta_{12} \mathbf{X}_{2}+\beta_{22} T_{1}+\sum_{k=1}^{K} \beta_{22} I_{k}\left(t_{2}\right)+\varepsilon_{2}
$$

where $t_{2}$ denotes realizations of the stochastic duration of the spell since the first birth. In 
both equations (2) and (3), $\varepsilon$ denotes the unobserved random factors that affect the transitions to the first and to the second birth, respectively. The specification in (3) includes the duration until the first birth, denoted as $T_{1}$, where the coefficient $\beta_{22}$ on this variable identifies the true tempo effects. In particular, $\beta_{22}>0$ is consistent with a catchup effect while $\beta_{22}<0$ with a postponement effect. The effect of duration dependence is modeled by using the yearly time dummies $I_{k}\left(t_{2}\right)$, where $t_{2}$ denotes realizations of the stochastic duration of the spell since the year of the first birth until the second birth, and $k=(1, \ldots, K)$ refers to the year intervals since the first birth. ${ }^{14}$

Using the hazard functions in equation (1), the contribution to the likelihood can be defined for each individual. Let $T_{j}^{0}$ denote the observed censored duration for $j=1,2$ so that $T_{j}^{0}=T_{j}$ if $T_{j}<C_{j}$ and $T_{j}^{0}=C_{j}$ otherwise, where $C_{j}$ is the censored observed duration. The contribution of a completed spell is given by the conditional density function

$$
f_{j}\left(t_{j} \mid \cdot\right)=\lambda_{j}\left(t_{j} \mid \cdot\right) \prod_{t_{j}=1}^{T_{j}^{0}-1}\left(1-\lambda_{j}\left(t_{j} \mid \cdot\right)\right)
$$

while the contribution of a censored spell is given by the conditional survival function ${ }^{15}$

$$
S_{j}\left(t_{j} \mid \cdot\right)=\prod_{t_{j}=1}^{T_{j}^{0}}\left(1-\lambda_{j}\left(t_{j} \mid \cdot\right)\right) .
$$

The total sample likelihood is given by the product of the individual likelihoods

\footnotetext{
${ }^{14}$ Although our specification of the transition to both the first and the second birth is based on a proportional hazard model, Brinch (2007) shows that variation in covariates overtime combined with variation across observations is sufficient to ensure identification without the proportional hazard assumption.

${ }^{15}$ Censored spells are contributed both by relatively "young" women, that is those who still have to complete their reproductive careers, and by women who drop from the panel due to panel attrition.
} 


$$
L\left(\theta, \varepsilon_{1}, \varepsilon_{2}\right)=\prod_{i=1}^{N} L_{1}\left(\theta_{1}\right) L_{2}^{c_{1}}\left(\theta_{2}\right) d G\left(\varepsilon_{1}, \varepsilon_{2}\right)
$$

where $L_{j}(\theta)=\left[f_{j}\left(t_{j} \mid \cdot\right)\right]^{c_{j}}\left[S_{j}\left(t_{j} \mid \cdot\right)\right]^{1-c_{j}}, \theta_{1}$ and $\theta_{2}$ are the parameters to be estimated, $N$ is the number of individual spells and $c_{j}$ are dummies that take the value one for a completed spell $\left(T_{j}<C_{j}\right)$ and zero for a censored spell $\left(T_{j}=C_{j}\right)$. Note that the spells for the second birth contribute to the likelihood when the spell for the first birth is not censored (i.e. $\left.c_{1}=1\right)$.

The unobserved heterogeneity distribution $G\left(\varepsilon_{1}, \varepsilon_{2}\right)$ is defined flexibly as a discrete distribution with support points denoted by $e_{j p}$ and the corresponding probability mass given by $\operatorname{Pr}\left(\varepsilon_{j}=e_{j p}\right)=\pi_{p}$, where $p=1, . ., P$ denotes the support points. This approach in modeling unobserved heterogeneity is used frequently in labor economics and originates from Heckman and Singer (1984) and is used in Heckman et al. (1985) and Heckman and Walker (1990) who study fertility dynamics. Each unobserved factor is assumed to be time-invariant and individual specific, and it is allowed to be correlated across transitions but it is assumed to be exogenous with respect to the other regressors. With two mass points for each unobserved component (random effects), there may be four types of individuals that are different in terms of their inclination to reach the first and the second parity because they have, for instance, a different desired fertility

$$
\begin{array}{ll}
\operatorname{Pr}\left(\varepsilon_{1}=e_{11}, \varepsilon_{2}=e_{21}\right)=\pi_{1}, & \operatorname{Pr}\left(\varepsilon_{1}=e_{11}, \varepsilon_{2}=e_{22}\right)=\pi_{2}, \\
\operatorname{Pr}\left(\varepsilon_{1}=e_{12}, \varepsilon_{2}=e_{21}\right)=\pi_{3}, & \operatorname{Pr}\left(\varepsilon_{1}=e_{12}, \varepsilon_{2}=e_{22}\right)=\pi_{4},
\end{array}
$$

where $0 \leq \pi_{p} \leq 1, \quad \sum_{p=1}^{4} \pi_{p}=1$ with $p=1, . .4$ and $\pi_{p}=\exp \left(\alpha_{p}\right) / \sum_{p=1}^{4} \exp \left(\alpha_{p}\right)$ with 
normalization $\alpha_{4}=0$ to have a multinomial logit specification. ${ }^{16}$

The sample log-likelihood can be written as follows

$$
\log L=\sum_{p=1}^{4} \pi_{p} \log L_{p},
$$

where $\log L_{p}$ is defined as in (6) for a specific mass point $p$. In the presence of a constant term in the vector of the observed covariates, we normalize the first mass point $e_{j 1}$ to zero, so that the estimated coefficient for the second mass point denotes the deviation from the constant term.

Identification of multistate discrete-time duration models is discussed by Cameron and Heckman (1998). They show that identification is enhanced if the index varies with duration without the need of exclusion restrictions. This condition is satisfied in the presence of time variant regressors in $\mathbf{X}_{1}$ and $\mathbf{X}_{2}$. Even with a constant index they show that the model is identified if attention is restricted to finite mixture distributions of the type defined above. It is important to note that the data do not provide observations on drawing from the mixing distribution of unobserved characteristics $G$ in (6). The information on $G$ comes from the observed interaction between duration and the observed individual characteristics. By allowing for the unobserved factors to be correlated across the two transitions, we control for potential selectivity which might confound the effect of the age at first birth on the transition to the second.

\footnotetext{
${ }^{16}$ We have also considered three mass points in the empirical analysis, but either they did not improve the estimation results, or they could not be identified.
} 


\section{Results}

We estimate the model for the transitions to the first and the second childbirth under two different assumptions. The first, which is the benchmark case, uses the "piecemeal approach" and assumes that the transitions to the first and the second parity are independent. The second allows for dependence across transitions by way of correlated unobserved heterogeneity, as discussed in the previous section.

The index for the transition to the first birth includes both time-variant and timeinvariant regressors. The time-variant variables are a dummy for being engaged in fulltime education, marital status (single, married and divorced) and a quadratic for years since first job, which is a proxy for potential working experience. The time-variant variables are constructed using the age of leaving school, age of last change of marital status and age of entering for the first time the labor market, which are observed in the first wave and are updated since then. The time invariant variables include the highest educational level achieved and a dummy equal to one for women who have been employed at least once and zero for those who have never worked in paid-employment in their life.

The highest educational level achieved is classified in three levels according to the International Standard Classification of Education (ISCED): "higher" for recognized higher education, "medium" for second stage of secondary education and "low" for lower than upper secondary education. For those women who have not yet completed education, this variable captures the effect of the expected level of education.

We use two proxies of labor force attachment. The first uses the time-invariant information on having ever been employed. We prefer this time-invariant variable to the 
time-variant current employment status mainly for two reasons. First, the information on individual labor market status is only observed for 1994-2001, so it is not available for the whole period from age 17 to the time of first childbirth for all women. Hence, estimating a specification including the current labor force status would require focusing only on the period 1994-2001 and on the women aged 17 in 1994 who experienced two childbirths in the same period, which would restrict considerably the sample size and would impose an arbitrary sample selection according to the spacing of the first two births. $^{17}$ Second, the variable on having been employed can be considered as predetermined with respect to the timing of fertility, and especially the timing of the second birth, compared to the current labor force status, which is clearly endogenous. Indeed, in developed countries, where age at motherhood is relatively high, being employed at least once in the life-time is less likely to be hindered by motherhood.

The drawback of using the time-invariant information on having been employed is that in some countries a very high percentage of women "has been employed". We consider, therefore, a second proxy of labor market attachment by combining the information on having been employed with the educational level, which is a more restrictive indicator of being career oriented. In particular, we consider women who have been employed and have upper secondary or higher education as being career oriented; as opposed to women who have either never being employed or have been employed but are low educated. As it is well known, education is a primary predictor of labor force participation and labor market attachment, both for women in general and for mothers

\footnotetext{
${ }^{17}$ For the same reason, we do not include partners' characteristics. Also in line with the previous empirical literature on tempo effects, we do not account for the potential endogeneity of educational variables. This means, for instance, that the coefficient on educational variables could also proxy for an individual's preference towards childbearing. By including the higher education achieved in both the first and the second birth equations we aim to capture the effect of age at first birth on the timing of the second birth over and above the association between age at first birth and the level of completed education.
} 
(see Bratti, 2003). Compared to the first proxy, this definition of career oriented women as a proxy for labor market attachment has more variation both within and across countries (see Table 1$){ }^{18}$

The specification for the transition to the second birth includes the same controls as those for the first childbirth, except for the student status dummy. The student status indicator, which is time variant, is only included in the transition to the first birth, as studying is generally not compatible with childrearing and, once we control for the level of education achieved, is aimed to capture a purely mechanical effect on delaying first birth (Gustafsson et al, 2002). In addition, the transition to the second birth includes the age at which a woman first gave birth, which captures the tempo effect, and a dummy variable for the first child being male to account for potential gender bias towards either sons or daughters.

Finally, we include year dummies in both equations to capture time-varying changes in policies or macro-economic conditions which might affect fertility decisions, and duration dependence dummies.

\subsection{Transition to the first birth}

Table A2 in the Appendix shows the estimation results from the benchmark case based on the assumption of independent transitions. ${ }^{19}$ Starting with the transition to the first birth, characteristics which are generally associated with a delay of the first childbirth are: being a student; having completed higher education; and having been employed. The

\footnotetext{
${ }^{18}$ It should be noted that both definitions of career orientation do not necessarily imply that women must be continuously attached to the labor force. Indeed, a sufficient condition for observing career effects would be that working women who delayed their first birth have accumulated more resources to afford a further birth, even if they decided to drop the labor force after their first childbirth.

${ }^{19} \mathrm{We}$ do not describe in detail the estimates of the transition to the first parity, since they do not represent the main focus of our paper. Delaying of first birth in Europe has been recently investigated by Nicoletti and Tanturri (2008).
} 
effect of the student status is in line with the idea that studying and childbearing can be hardly combined and that studying has a mechanical effect on delaying the first child. Higher and medium levels of completed education also have negative effects in all countries except in Denmark and Germany. This result suggests that the pure mechanical effect of being a student is not the only relevant dimension in delaying fertility produced by education. It rather shows that in several countries the "career planning" and the "consumption smoothing" motives (see Gustafsson, 2001) for more educated women contribute to the delay of the first childbirth. This is also suggested by the negative effect of the proxy for attachment to the labor market - the effect of having been employed - and the inverse- $U$ shaped pattern of the effect of women's earnings potential proxied by potential experience. This indicates that women face a higher hazard of childbirth as they get more experience in the labor market, when childbearing is less damaging to their future careers and current household income is relatively higher. Finally, the effect of being married or having been married but now divorced go in the expected direction of increasing the hazard of giving birth to the first child.

\subsection{The effect of age at first birth on the transition to the second birth}

We now turn to the main interest of the paper, which is the effect of delaying the first birth on the transition to the second birth. Estimation results in Table A2 show that the effect of delaying the first birth on the hazard of the second one varies across countries. For all Southern European countries (Greece, Italy, Portugal and Spain), we find a statistically significant postponement effect on the overall population as the coefficient on the age at first birth is negative. That is, giving birth to the first child at an older age has a negative effect on the hazard of achieving a second birth. We also find a negative effect 
of age at first birth for Ireland and the U.K. and positive effects for Belgium, Denmark and France, which are, however, statistically insignificant.

We also consider how the effect of age at first birth differs as women age by allowing for non-linear effects. We report in the paper, however, only the linear specifications since they are qualitatively similar with the non-linear specification. In addition, they are less sensitive to small cell size problems that are likely to affect the specification using age intervals, and are directly comparability with the previous literature. For the non-linear specification we estimate the model by introducing age group dummies: 17-20 (reference), 21-25, 26-29 and above 30. We find a non-linear effect for some countries, which is more pronounced after age 30. For example, we observe a significant catch-up effect in France for age at birth $30+$, and a significant postponement effect for Greece, Italy, Portugal and Spain, which is increasing as women age. This is consistent with an "age deadline", which might become increasingly important as women age

To distinguish between a true causal effect of age at first birth from a spurious correlation due to unobserved heterogeneity, we estimate the two transitions jointly as in equation (6). The coefficient estimates in specification 1 of Table 2 suggest that conditional on observed and unobserved heterogeneity, delaying the first birth lowers the transition to the second parity in Greece, Ireland, Italy, Portugal, Spain and the U.K. ${ }^{20}$ The postponement effect, however, is statistically significant only for Greece, Portugal and Spain. We also find for Denmark and France that accounting for endogeneity of age at first birth leads to a significant catch-up effect: delaying the first birth positively affects

\footnotetext{
${ }^{20}$ We only report in Table 2 the main variables of interest for the transition to the second birth. The full estimates from the jointly estimated model of specification 1 for both transitions are reported in Table A3 in the Appendix. Specification 1 of Table A3 is equivalent to the one of Table A2 based on the piecemeal approach.
} 
the transition to the second birth. The findings for Denmark are consistent with those in Heckman et al. (1985) and Heckman and Walker (1990) for Sweden, another Nordic country with similar institutional characteristics.

\section{(Insert table 2 here)}

Table 3 shows the estimates of the unobserved heterogeneity distribution and the associated probabilities. The unobserved heterogeneity allows us to split a country's population among four different individual types: 1 ) fast parity achievers $(\mathrm{HH})$, who are fast in achieving both parities; 2) slow parity achievers (LL), who are slow in achieving both parities; 3) slow 1st parity achievers (LH), who are relatively slow in achieving the first parity but faster in achieving the second one; and 4) slow 2nd parity achievers (HL), who are relatively fast in achieving the first parity but slower in achieving the second.

\section{(Insert table 3 here)}

In Belgium, Denmark, France, Germany, Greece, Ireland, Portugal and Spain, the largest fraction of the population is composed of HH-type individuals, i.e. those who are relatively fast in achieving both parities. Among these countries, the largest fraction of fast achievers is observed for Ireland, which is also the country with the highest share of women with more than one child in our sample. By contrast, in Italy and the U.K., the largest part of the population is represented by HL-type individuals: those who are fast in achieving the first parity but slow in achieving the second one. We also observe other differences in unobserved heterogeneity by country. For instance, in France and Greece, the second largest group in the population is represented by slow parity achievers. In other countries such as Belgium, Germany, Portugal and Spain, the second largest group is instead composed of HL-type individuals. 


\subsection{Explaining the cross-country variation in tempo effects}

The previous analysis has revealed significant heterogeneity across countries for the effect of age at first birth on the timing of the following birth, with a significant postponement effect emerging in Southern Europe and a catch-up effect found in Denmark and France. As we discussed in section 2, cross-country differences are likely to be determined by the relative magnitudes of biological, socio-cultural and career effects, which are likely to operate differentially both on career and non-career oriented women and across countries. Hence, in order to have an idea of the relative importance of these effects, we estimate a specification in which age at first birth is interacted with the two proxies of labor force attachment (specifications 2 and 3 of Table 2).

The effect of delaying motherhood for non-career oriented women, which is captured by the non-interacted coefficient of the age at first birth on the hazard of the second parity, is negative in all countries except for Belgium (specifications 2 and 3), and Germany and the U.K. (specification 2), where it is positive but not statistically different from zero. This shows the existence of postponement effects on non-career oriented women in a number of countries. It is interesting to note that the magnitude of the postponement effect varies across countries and it is higher and significant in Ireland and Southern European countries (Greece, Portugal, Italy and Spain). One possible way to rationalize this variation is in terms of differential socio-cultural effects across countries: some countries' social norms are likely to determine a larger social penalty for giving birth late. The fact that we do not find a postponement effect for non-career oriented women in Germany, for instance, where the regulation regarding assisted reproductive technologies is very strict (Langdridge and Blyth, 2001), while we find a 
very strong effect in Greece, where a laissez faire approach prevails, might suggest that the biological effect is not the main driver of the cross-country differences in these postponement effects, and that socio-cultural differences may represent a more relevant explanation.

Estimates from specifications 2 and 3 of Table 2, show that career-oriented women are overall significantly less likely to progress to the second parity. ${ }^{21}$ The negative effect is likely to capture the higher opportunity cost of childbearing for careeroriented women. Although career-oriented women are less likely to progress to the second parity, delaying the first birth has a differential positive effect. The interaction term between the proxy for labor force attachment and age at first birth is meant to capture the career effect on the timing of the second birth that might be produced by delaying motherhood, which was discussed in section $2 .{ }^{22}$ The sign and magnitude of this career effect determines the sign of the overall effect of delaying the first birth for women more attached to the labor market (i.e. the sum of the main effect of age at first birth and the interaction term with being career-oriented). In countries such as Denmark, France and Germany (specification 3), where the positive career effect is relatively larger than the negative effect related to the socio-cultural and biological effects, the overall effect is positive and significant (catch-up effect). In contrast, in countries such as Greece, Italy, Portugal and Spain, where the positive career effect is relatively small compared to the socio-cultural influences, the overall effect is negative (postponement effect).

Specification 3 in Table 2, using the stricter definition of labor force attachment,

\footnotetext{
${ }^{21}$ For specification 2 the effect is positive but not significant for Belgium, Germany and the U.K., while for specification 3 the effect is negative but again not significant for Belgium, Germany and Greece.

${ }^{22}$ The effect of age at first birth for Denmark refers to those women who have been employed. The effect of having been employed cannot be identified due to low variation, as most of women have been employed at least once in their lifetime.
} 
shows that for most countries where we found significant tempo effects in specification 2 (France, Greece, Italy, Portugal and Spain) the main results are qualitatively and quantitatively similar. As for the career effect, it is worth noting the large and significant effect of the interaction term for Germany, which now suggests an overall catch-up effect. Higher career effects are now also observed for Italy and Portugal, when we consider working women with higher education. The overall effect for these women is then positive but not significant. Overall, we consider this as evidence that our results are robust to alternative definitions of career oriented women.

As we have already discussed in section 2, the relative difference in the sign and magnitude of the career effect across countries might be explained by differences in their labor markets and childcare provisions. We consider further the role of institutions in Section 5.6.

\subsection{Sensitivity analysis}

In order to investigate the potential effect of panel attrition on our estimates we also estimated the model focusing on the pre-1994 fertility history only, which is not affected by panel attrition. The results are qualitatively and quantitatively similar but the effects are less precisely estimated due to the reduced sample size.

Moreover, although our econometric model takes into account right-censored cases in the likelihood function, we have checked the sensitivity of our results by considering the sub-sample of women aged 32-37 in the first observed wave. These women will be age 40 or older by the end of the survey. Our findings are robust to this sensitivity check. In particular, we find significant postponement effects in the South and catch-up effects in the North. 
Finally, we considered lagged values of the time-varying regressors (student status, marital status, working experience) to account for the potential simultaneity of births with these variables. Again the results are robust. ${ }^{23}$

\subsection{Simulations}

The above analysis has shown that there are statistically significant tempo effects in some European countries and that their magnitude and sign vary across countries. To gauge the magnitude of these effects on fertility, we compute the conditional probability to progress to the second birth within five years after the first birth under different scenarios with respect to the age at first birth. The first scenario is when the age at first birth is 25 , which is close to the average observed in most European countries during the period we analyzed. The second scenario is where the age at first birth increases to 30 . We distinguish between career and non-career oriented women based on specification 2, and we fix other characteristics at their mean sample values at the country level.

Table 4 reports the difference in the probability in having a second childbirth within five years of the first birth, induced by a change in the age at first birth from 25 to 30. The effects are estimated by women's working status and by country. Here we comment only on the effects that were found to be statistically significant. It can be seen immediately the large catch-up effects for working mothers in Denmark and France, where delaying age at motherhood by five years leads to an increase in the likelihood of having a second childbirth within the following five years by almost 20 percentage points (p.p.) and 12 p.p., respectively. Catch up effects are also observed for working women in other countries, although they are much smaller in magnitude. As for non-working

\footnotetext{
${ }^{23}$ These results are available by the authors upon request.
} 
women, our simulations predict large postponement effects for Greece (-11.5 p.p.), Ireland (-10.6 p.p.) and Italy (-7.1 p.p), and smaller effects for Spain and Portugal (-5.5 and -3.2 p.p., respectively).

\section{(Insert table 4 here)}

\subsection{A pooled cross-country analysis}

The main conclusion from the single country analysis is that European countries may be broadly divided between those in which the postponement effect prevails, mainly the Southern European countries, and those in which delaying motherhood has a nonnegative or even a positive effect on the transition to the second childbirth, i.e. Northern or Central European countries. This "North-South" divide has been already observed by many researchers (Esping-Andersen, 1990, Bettio and Villa, 1998, Gauthier, 2002) and reflects differences between countries in which there is a traditional view of the role of the woman and where women find it difficult to reconcile family and work, and countries that have gone a long way in ensuring an active role of women in the labor market through family friendly policies.

In this section we try to establish a closer link between the differences in the tempo effects across countries and specific institutional characteristics that reflect socioeconomic and cultural differences. We perform additional analyses on the pooled-country sample and exploit the institutional variation across countries. We focus on the transition to the second birth and estimate the effect of age at first birth and its interaction with some institutional characteristics, which are related to the causal pathways that we discussed in section 2.

We first classify countries into two groups (North and South) and we test whether 
the postponement effect differs between these two groups. The first column in Table 5 shows that delaying the first birth has a significant negative effect on the probability of a second birth. The coefficient on the main effect for living in the North reveals that women in Northern countries are significantly more likely to experience a second childbirth. Most importantly, the interaction of North with age at first birth shows a positive and significant catch-up effect for women in the North.

\section{(Insert table 5 here)}

The rest of Table 5 presents the effect of various country characteristics on the transition to the second birth. We consider family friendly policies such as the share of part-time employment, the length of maternal leave, and the public expenditures on child care as a percentage of GDP. ${ }^{24}$ We also consider economic variables such as the unemployment rate and average female wages. Finally, we consider the potential role of socio-cultural influences, which are proxied by the fraction of Christian Catholic and Orthodox populations present in a country. These religions are usually associated to a more traditional view of the woman and the family, and tend to be against the use of many ARTs, such as in vitro fertilization (IVF). ${ }^{25}$ Due to the high correlation between the different characteristics, which mimic the North-South divide and causes severe multicollinearity problems, we estimate our main specification including one characteristic at the time.

Starting with the family friendly policies, we observe that a higher share of parttime opportunities, longer maternal leave and higher public expenditures on child care

\footnotetext{
${ }^{24}$ A description of the variables used and the relative data sources are reported in the footnote of Table 5. For the series that do not cover the whole time period of fertility histories that we consider (1976-2001) we use the first observed value for all years of the unobserved period (that is the period not covered by the time-series). In case of missing values within the "observed" period, we use the mean between the first observed year preceding the missing year and the first observed following year.

${ }^{25}$ See http://www.ivf-worldwide.com/Education/ivf-global-perspective-religious.html.
} 
have a positive and significant effect on the probability of a second birth. ${ }^{26}$ These effects are reported as the coefficients of the "main effect" in Table 5. Women who delay the first birth are less likely to progress to the second parity as the coefficient of age at first birth is negative and significant in all the regressions. However, the interaction of age at first birth with each institutional characteristic in columns 2-4 is positive and significant, which suggests that a higher availability of family friendly policies raises the probability of having a second birth for women who delay their first birth. A similar pattern is observed when we consider the average female wage, which suggests a dominant income effect on fertility leading to a catch-up effect. On the other hand, a higher unemployment rate is associated with a lower probability of a second birth. This is in line with Da Rocha and Fuster (2006). Finally, religions with a more traditional view of the role of women are associated with a lower transition to the second birth, especially for those women who have delayed their first birth.

\section{Conclusion}

We investigate the effect of delaying motherhood on the transition to the second birth for a number of European countries using highly comparable data from the European Community Household Panel. We address the potential endogeneity of age at first birth by estimating a multistate discrete-time duration model, which accounts for correlated unobserved heterogeneity across parities. Using single-country analyses, we show that the effect of delaying motherhood differs both across countries and with the degree of women's labor force attachment. For women with low labor force attachment, delaying the first birth is likely to lower the likelihood of progressing to the second parity because

\footnotetext{
${ }^{26}$ Lalive and Zweimüller (2009) find that parental leave extensions affect positively fertility.
} 
of biological and socio-cultural factors. For women who are strongly attached to the labor market, the career-planning motive to delay the first birth - which is associated with more labor market experience and higher earnings - could raise instead the likelihood of progressing to the second parity due to an income effect on fertility. This higher transition to the second birth occurs when the career effect is large enough to offset the negative biological and socio-cultural effects acting on all women.

These two opposite forces produced by delaying the first birth on the transition to the second child co-exist and have different magnitudes depending on countries' institutional features determining the overall sign of tempo effects. The positive career effect is found to be larger in countries with high childcare provision and availability of part-time opportunities, and where family and work can be more easily reconciled, such as Denmark, France and Germany leading overall to a catch-up effect in the population. The negative biological and socio-cultural effect is found to be higher in Southern European countries and Ireland, where social norms inflict a relatively larger social penalty for giving birth late, leading overall to a postponement effect. As for the magnitude of these tempo effects, our estimates suggest that delaying age at motherhood by five years - from 25 to 30 - leads to a positive (catch-up) effect on the likelihood of having a second childbirth within five years from the first of as much as 19 percentage points for countries such as Denmark, and a negative (postponement) effect of as much as -12 percentage points in Southern European countries such as Greece.

These findings are confirmed by a pooled-country analysis, which exploits the institutional variation across countries and over time. First, women in Northern countries are significantly more likely to experience a second childbirth. Most importantly, the 
interaction of living in the North with age at first birth shows a positive and significant catch-up effect. This North-South divide seems to be related to institutional differences. Women who delay their first birth are less likely to progress to the second parity but a higher availability of family friendly policies (part-time opportunities, long maternal leave, availability of public child care, wage levels) raises the probability of having a second birth for those women. 


\section{References}

Ahn N, Mira P (2002) A note on the changing relationship between fertility and female employment rates in developed countries. Journal of Population Economics 15(4): 667-682

Amuedo-Dorantes C, Kimmel J (2005) The motherhood wage gap for women in the United States: The importance of college and fertility delay. Review of Economics of the Household 3(1): 17-48

Apps P, Rees R (2004) Fertility, taxation and family policy. Scandinavian Journal of Economics 106(4): 745-763

Bettio F, Villa P (1998) A Mediterranean perspective on the breakdown of the relationship between participation and fertility. Cambridge Journal of Economics 22(2): 137-171

Billari FC, Kohler H-P, Andersson G, Lundström H (2007) Approaching the limit: longterm trends in late and very late fertility. Population and Development Review 33(1): $149-170$

Blackburn ML, Bloom DE, Neumark D (1993) Fertility timing, wages and human capital. Journal of Population Economics 6(1): 1-30

Bongaarts J (2001) Fertility and reproductive preferences in post-transitional societies. Population and Development Review, 27(Supplement): 260-281

Bratti M (2003) Labour force participation and marital fertility of Italian women: the role of education. Journal of Population Economics 16(3): 525-554

Brinch CS (2007) Nonparametric identification of the mixed hazards model with timevarying covariates. Econometric Theory 23(2): 349-354

Cameron SV, Heckman JJ (1998) Life cycle schooling and dynamic selection bias: models and evidence for five cohorts of American males. Journal of Political Economy 106(2): 262-333

Cigno, A, Ermisch JJ (1989) A microeconomic analysis of the timing of births. European Economic Review 33(4): 737-760

Da Rocha JM, Fuster L (2006) Why are fertility rates and female employment ratios positively correlated across O.E.C.D. countries? International Economic Review 47(4): 1187-1222

Davies R, Pierre G (2005) The family gap in pay in Europe: a cross-country study. Labour Economics 12(4): 469-486

Del Boca D, Pasqua S, Pronzato C (2009) Motherhood and market work decisions in institutional context: a European perspective. Oxford Economic Papers 61(suppl. 1): i147-i171

Del Boca D, Sauer RM (2009) Life cycle employment and fertility across institutional environments. European Economic Review 53(3): 274-292

Del Bono E, Weber A, Winter-Ebmer R (2008) Clash of career and family: Fertility decisions after job displacement. IZA Discussion Paper 3272, Institute for the Study of Labor (IZA), Bonn

Esping-Andersen G (1990) The Three Worlds of Welfare Capitalism. Polity Press, Cambridge, UK. 
Fernandez R., Fogli A (2006) Culture: an empirical investigation of beliefs, work, and fertility. American Economic Journal: Macroeconomics 1(1): 146-177

Fernandez R, Fogli A (2009) Fertility: the role of culture and family experience. Journal of the European Economic Association 4(2-3): 552-561

Francesconi M (2002) A joint dynamic model of fertility and work of married women. Journal of Labor Economics 20(2): 336-380

Gauthier AH (2002) Family policies in industrialized countries: is there convergence? Population 57(2): 447-74

Gustafsson S (2001) Optimal age at motherhood. Theoretical and empirical considerations on postponement of maternity in Europe. Journal of Population Economics 14(2): 225-47

Gustafsson S, Kenjoh E, Wetzels C (2002) The role of education on postponement of maternity in Britain, Germany, the Netherlands, Sweden. In: Ruspini E, Dale A (ed) The gender dimension of social change: The contribution of dynamic research to the study of women's life courses. Bristol: The Policy Press 55-79

Heckman JJ, Hotz VJ, Walker J (1985) New evidence on the timing and spacing of births. American Economic Review 75(2): 179-184

Heckman JJ, Singer B (1984) The identifiability of the proportional hazard model. Review of Economic Studies 51(2): 231-241

Heckman JJ, Walker J (1990) The third birth in Sweden. Journal of Population Economics 3(4): 235-275

Hotz VJ, Miller RA (1988) An empirical analysis of life cycle fertility and female labor supply. Econometrica 56(1): 91-118

Kohler H, Billari FC, Ortega JA (2002) The emergence of lowest-low fertility in Europe during the 1990s. Population and Development Review 28(4): 641-680

Kohler HP, Skytthe A, Christensen K (2001) The age at first birth and completed fertility reconsidered: findings from a sample of identical twins. MPIDR Working Paper 2001-006. Max Planck Institute for Demographic Research, Rostock

Lalive R, Zweimüller J (2009) Does parental leave affect fertility and return-to-work? Evidence from two natural experiments. Quarterly Journal of Economics 58(6): 1363-1402

Lancaster T (1990) The Econometric Analysis of Transition Data. Cambridge University Press, Cambridge

Langdridge D, Blyth E (2001) Regulation of assisted conception services in Europe : Implications of the new reproductive technologies for "the family". Journal of Social Welfare and Family Law 23(1): 45-64

Lutz W, Skirbekk V (2005) Policies addressing the tempo effect in low-fertility countries. Population and Development Review 31(4): 699-720

Martínez DF, Iza A (2004) Skill premium effects on fertility and female labor force supply. Journal of Population Economics 17(1): 1-16

Miller A (forthcoming) The effects of motherhood timing on career path, Journal of Population Economics. Published online: DOI No. 10.1007/s00148-009-0296-x. 
Moffitt R (1984) Profiles of fertility, labour supply and wages of married women: A complete life-cycle model. Review of Economic Studies 51(2): 263-78

Morgan SP, Rindfuss RR (1999) Reexamining the link of early childbearing to marriage and to subsequent fertility. Demography 36(1): 59-75

Nicoletti C, Tanturri ML (2008) Differences in delaying motherhood across European countries: empirical evidence from the ECHP. European Journal of Population 24(2): 157-183

van den Berg GJ (2001) Duration models: specification, identification and multiple durations. In: Heckman JJ, Leamer E (ed) Handbook of Econometrics, vol. V. North-Holland, Amsterdam (Chapter 55).

van Ours JC (2003) Is Cannabis a stepping-stone for cocaine? Journal of Health Economics 22(4): 539-554

van Ours JC (2004) A pint a day raises a man's pay; but smoking blows that gain away. Journal of Health Economics 23(5): 863-886

Walker JR (1995) The effect of public policies on recent Swedish fertility behavior. Journal of Population Economics 8(3): 223-251. 
Table 1. Institutional details and summary statistics.

\begin{tabular}{|c|c|c|c|c|c|c|c|c|c|c|}
\hline & Belgium & Denmark & France & Germany & Greece & Ireland & Italy & Portugal & Spain & UK \\
\hline$\%$ child-care coverage $(0-3$ years old $)$ & 30 & 64 & 29 & 10 & 3 & 38 & 6 & 12 & 5 & 34 \\
\hline$\%$ child-care coverage ( $3-6$ years old) & 97 & 91 & 99 & 78 & 46 & 56 & 95 & 75 & 84 & 60 \\
\hline$\%$ part-time & 36.9 & 34.7 & 31.4 & 37.2 & 10.0 & 30.1 & 15.6 & 16.7 & 17.1 & 44.0 \\
\hline sample size & 718 & 537 & 810 & 737 & 1232 & 880 & 1801 & 1018 & 1689 & 898 \\
\hline$\%$ has been employed & 94.84 & 98.88 & 92.83 & 75.84 & 76.94 & 95.79 & 72.62 & 84.57 & 87.98 & 95.87 \\
\hline$\%$ career-oriented & 72.56 & 94.59 & 64.19 & 59.43 & 52.19 & 63.86 & 44.19 & 25.44 & 47.06 & 49.88 \\
\hline$\%$ women with more than 1 child & 52.47 & 46.03 & 57.01 & 38.54 & 63.16 & 63.84 & 40.97 & 48.97 & 46.66 & 49.60 \\
\hline Mean age at first birth & 26.07 & 26.87 & 25.17 & 25.21 & 24.07 & 25.89 & 26.16 & 23.86 & 25.79 & 26.25 \\
\hline$\%$ childless (at age $35+$ ) & 14.35 & 14.01 & 13.55 & 18.54 & 13.10 & 13.70 & 20.31 & 14.63 & 18.10 & 17.54 \\
\hline$\%$ childless (at age $36+$ ) & 12.45 & 13.96 & 13.23 & 17.75 & 12.13 & 12.50 & 19.00 & 12.77 & 16.53 & 15.86 \\
\hline$\%$ childless (at age $37+$ ) & 11.38 & 12.83 & 13.17 & 15.92 & 11.64 & 11.32 & 16.96 & 11.76 & 15.75 & 15.65 \\
\hline$\%$ childless (at age $38+$ ) & 11.05 & 12.80 & 12.77 & 16.05 & 10.81 & 10.07 & 15.72 & 11.56 & 15.24 & 15.03 \\
\hline$\%$ childless (at age $39+$ ) & 10.81 & 12.37 & 12.84 & 13.96 & 10.56 & 8.97 & 13.90 & 10.44 & 15.19 & 15.02 \\
\hline
\end{tabular}

Source. Child care data from Employment Outlook (2001). The data for coverage refer to the proportion of young children using formal child-care arrangements which include both public and private provision, data for the UK refer to England only; part-time data from Eurostat (1999); \% has been employed from ECHP (1994-2001); \% career oriented (i.e. has been employed and has upper secondary or higher education) from ECHP(1994-2001); \% women with more than one child and mean age at first birth from ECHP (1994-2001), only for women aged 35+ at the last observed wave; \% childless, at various ages, from ECHP(19942001). 
Table 2. The effect of age at first birth on the transition to the second birth.

\begin{tabular}{|c|c|c|c|c|c|c|c|c|c|c|}
\hline & Belgium & Denmark & France & Germany & Greece & Ireland & $\overline{\text { Italy }}$ & Portugal & Spain & $\overline{\mathrm{UK}}$ \\
\hline \multicolumn{11}{|l|}{ Specification 1} \\
\hline Age at First Birth & $\begin{array}{c}0.048 \\
(0.039)\end{array}$ & $\begin{array}{c}0.133 \\
(0.040)\end{array}$ & $\begin{array}{c}0.057 \\
(0.030)\end{array}$ & $\begin{array}{c}0.006 \\
(0.027)\end{array}$ & $\begin{array}{l}-0.037 \\
(0.018)\end{array}$ & $\begin{array}{l}-0.039 \\
(0.034)\end{array}$ & $\begin{array}{l}-0.021 \\
(0.017)\end{array}$ & $\begin{array}{l}-0.043 \\
(0.022)\end{array}$ & $\begin{array}{l}-0.046 \\
(0.017)\end{array}$ & $\begin{array}{l}-0.016 \\
(0.025)\end{array}$ \\
\hline Has Been Employed & $\begin{array}{c}0.135 \\
(0.421)\end{array}$ & - & $\begin{array}{l}-0.957 \\
(0.395)\end{array}$ & $\begin{array}{c}0.508 \\
(0.309)\end{array}$ & $\begin{array}{c}0.390 \\
(0.163)\end{array}$ & $\begin{array}{l}-0.545 \\
(0.664)\end{array}$ & $\begin{array}{l}-0.592 \\
(0.227)\end{array}$ & $\begin{array}{l}-0.844 \\
(0.222)\end{array}$ & $\begin{array}{c}0.103 \\
(0.228)\end{array}$ & $\begin{array}{c}-0.0693 \\
(0.446)\end{array}$ \\
\hline \multicolumn{11}{|l|}{ Specification 2} \\
\hline Age at First Birth & $\begin{array}{c}0.058 \\
(0.115)\end{array}$ & - & $\begin{array}{l}-0.061 \\
(0.067)\end{array}$ & $\begin{array}{c}0.003 \\
(0.039)\end{array}$ & $\begin{array}{l}-0.074 \\
(0.025)\end{array}$ & $\begin{array}{l}-0.195 \\
(0.053)\end{array}$ & $\begin{array}{l}-0.056 \\
(0.024)\end{array}$ & $\begin{array}{l}-0.089 \\
(0.048)\end{array}$ & $\begin{array}{l}-0.123 \\
(0.036)\end{array}$ & $\begin{array}{c}0.085 \\
(0.086)\end{array}$ \\
\hline Age at First Birth*Has Been Employed & $\begin{array}{l}-0.010 \\
(0.116)\end{array}$ & $\begin{array}{c}0.133 \\
(0.040)\end{array}$ & $\begin{array}{c}0.137 \\
(0.072)\end{array}$ & $\begin{array}{c}0.004 \\
(0.050)\end{array}$ & $\begin{array}{c}0.055 \\
(0.030)\end{array}$ & $\begin{array}{c}0.225 \\
(0.061)\end{array}$ & $\begin{array}{c}0.053 \\
(0.026)\end{array}$ & $\begin{array}{c}0.054 \\
(0.051)\end{array}$ & $\begin{array}{c}0.094 \\
(0.039)\end{array}$ & $\begin{array}{l}-0.107 \\
(0.087)\end{array}$ \\
\hline Has Been Employed & $\begin{array}{c}0.360 \\
(2.545)\end{array}$ & - & $\begin{array}{c}-3.792 \\
(1.536)\end{array}$ & $\begin{array}{c}0.416 \\
(1.151)\end{array}$ & $\begin{array}{l}-0.796 \\
(0.661)\end{array}$ & $\begin{array}{l}-5.290 \\
(1.150)\end{array}$ & $\begin{array}{l}-1.759 \\
(0.625)\end{array}$ & $\begin{array}{l}-2.008 \\
(1.116)\end{array}$ & $\begin{array}{l}-2.039 \\
(0.916)\end{array}$ & $\begin{array}{c}1.590 \\
(1.929)\end{array}$ \\
\hline \multicolumn{11}{|l|}{ Specification 3} \\
\hline Age at First Birth & $\begin{array}{c}0.033 \\
(0.050)\end{array}$ & $\begin{array}{l}- \\
-\end{array}$ & $\begin{array}{l}-0.003 \\
(0.036)\end{array}$ & $\begin{array}{l}-0.035 \\
(0.033)\end{array}$ & $\begin{array}{l}-0.057 \\
(0.021)\end{array}$ & $\begin{array}{l}-0.058 \\
(0.034)\end{array}$ & $\begin{array}{l}-0.049 \\
(0.017)\end{array}$ & $\begin{array}{l}-0.059 \\
(0.024)\end{array}$ & $\begin{array}{l}-0.082 \\
(0.021)\end{array}$ & $\begin{array}{l}-0.001 \\
(0.027)\end{array}$ \\
\hline Age at First Birth*Career & $\begin{array}{c}0.027 \\
(0.048)\end{array}$ & $\begin{array}{c}0.133 \\
(0.040)\end{array}$ & $\begin{array}{c}0.143 \\
(0.040)\end{array}$ & $\begin{array}{c}0.085 \\
(0.043)\end{array}$ & $\begin{array}{c}0.024 \\
(0.026)\end{array}$ & $\begin{array}{c}0.048 \\
(0.030)\end{array}$ & $\begin{array}{c}0.073 \\
(0.023)\end{array}$ & $\begin{array}{c}0.071 \\
(0.040)\end{array}$ & $\begin{array}{c}0.073 \\
(0.026)\end{array}$ & $\begin{array}{l}-0.007 \\
(0.027)\end{array}$ \\
\hline Career & $\begin{array}{l}-1.883 \\
(1.521)\end{array}$ & $\begin{array}{l}- \\
-\end{array}$ & $\begin{array}{l}-3.892 \\
(1.015)\end{array}$ & $\begin{array}{l}-1.599 \\
(1.103)\end{array}$ & $\begin{array}{l}-0.430 \\
(0.639)\end{array}$ & $\begin{array}{l}-2.161 \\
(1.079)\end{array}$ & $\begin{array}{l}-1.790 \\
(0.616)\end{array}$ & $\begin{array}{l}-2.552 \\
(1.225)\end{array}$ & $\begin{array}{l}-1.484 \\
(0.720)\end{array}$ & $\begin{array}{l}-2.356 \\
(1.040)\end{array}$ \\
\hline
\end{tabular}

Note: The table reports coefficient estimates with standard errors in parentheses from the bivariate duration model with correlated unobserved heterogeneity estimated for each country separately. Specification 2 allows for an interaction of age at first birth with ever being employed. Career in Specification 3 is defined as ever being employed with higher or medium level of education.Table A3 reports the coefficient estimates for other controls for specification 1. We also include year dummies to capture time-varying policies or macro-economic factors, and duration dependence dummies. For Denmark, in all specifications the effect of age at first birth refers to those women who have been employed. The variable has been employed could not be estimated due to low variation as most of women have been employed at least once in their life-time. 
Table 3. Estimates of unobserved heterogeneity distribution.

\begin{tabular}{|c|c|c|c|c|c|c|c|c|c|c|}
\hline & Belgium & Denmark & France & Germany & Greece & Ireland & Italy & Portugal & Spain & UK \\
\hline \multicolumn{11}{|l|}{ Duration to First Birth } \\
\hline \multirow[t]{2}{*}{$\mathrm{e} 1_{1}$} & -4.927 & -2.880 & -3.955 & -6.808 & -4.888 & -4.064 & -3.999 & -3.615 & -4.590 & -6.807 \\
\hline & $(0.893)$ & $(0.548)$ & $(0.558)$ & $(0.924)$ & $(0.235)$ & $(0.361)$ & $(0.156)$ & $(0.224)$ & $(0.189)$ & $(4.472)$ \\
\hline \multirow[t]{2}{*}{$\mathrm{e} 1_{2}-\mathrm{e} 1_{1}$} & 2.735 & -1.154 & 2.181 & 3.459 & -2.459 & -2.032 & -3.778 & -3.087 & -3.068 & 3.976 \\
\hline & $(0.764)$ & $(0.253)$ & $(0.411)$ & $(0.822)$ & $(0.405)$ & $(0.735)$ & $(0.578)$ & $(0.532)$ & $(0.484)$ & $(4.133)$ \\
\hline \multicolumn{11}{|l|}{ Duration to Second Birth } \\
\hline \multirow[t]{2}{*}{$\mathrm{e} 2_{1}$} & -5.314 & -6.018 & -1.940 & -1.994 & -1.082 & -0.859 & -2.414 & -2.788 & -2.424 & -1.704 \\
\hline & $(1.137)$ & $(0.990)$ & $(0.606)$ & $(0.697)$ & $(0.471)$ & $(0.833)$ & $(0.805)$ & $(1.536)$ & $(0.788)$ & $(0.636)$ \\
\hline \multirow[t]{2}{*}{$\mathrm{e} 2_{2}-\mathrm{e} 2_{1}$} & 2.655 & -inf & -2.089 & -inf & -inf & -1.795 & 1.605 & 2.849 & 1.820 & 1.457 \\
\hline & $(0.710)$ & - & $(0.809)$ & - & - & $(0.636)$ & $(0.229)$ & $(1.093)$ & $(0.429)$ & $(1.036)$ \\
\hline \multicolumn{11}{|l|}{ Probabilities } \\
\hline $\mathrm{P} 1\left(\varepsilon 1=\mathrm{e} 1_{1}, \varepsilon 2=\mathrm{e} 2_{1}\right)$ & $0.086(\mathrm{LL})$ & $0.547(\mathrm{HH})$ & $0(\mathrm{LH})$ & $0.057(\mathrm{LH})$ & $0.879(\mathrm{HH})$ & $0.907(\mathrm{HH})$ & $0.502(\mathrm{HL})$ & $0.216(\mathrm{HL})$ & $0.278(\mathrm{HL})$ & $0.090(\mathrm{LL})$ \\
\hline $\mathrm{P} 2\left(\varepsilon 1=\mathrm{e} 1_{1}, \varepsilon 2=\mathrm{e} 22_{2}-\mathrm{e} 2{ }_{1}\right)$ & $0(\mathrm{LH})$ & $0(\mathrm{HL})$ & $0.124(\mathrm{LL})$ & $0.073(\mathrm{LL})$ & $0.048(\mathrm{HL})$ & $0(\mathrm{HL})$ & $0.423(\mathrm{HH})$ & $0.725(\mathrm{HH})$ & $0.650(\mathrm{HH})$ & $0(\mathrm{LH})$ \\
\hline $\mathrm{P} 3\left(\varepsilon 1=\mathrm{e} 1_{2}-\mathrm{e} 1_{1}, \varepsilon 2=\mathrm{e} 2_{1}\right)$ & $0.195(\mathrm{HL})$ & $0.258(\mathrm{HL})$ & $0.818(\mathrm{HH})$ & $0.715(\mathrm{HH})$ & $0(\mathrm{LH})$ & $0(\mathrm{LH})$ & $0.073(\mathrm{LL})$ & $0.050(\mathrm{LL})$ & $0.071(\mathrm{LL})$ & $0.723(\mathrm{HL})$ \\
\hline $\mathrm{P} 4\left(\varepsilon 1=\mathrm{e} 1_{2}-\mathrm{e} 1_{1}, \varepsilon 2=\mathrm{e} 2_{2}-\mathrm{e} 2_{1}\right)$ & $0.719(\mathrm{HH})$ & $0.195(\mathrm{LL})$ & $0.058(\mathrm{HL})$ & $0.155(\mathrm{HL})$ & $0.073(\mathrm{LL})$ & $0.093(\mathrm{LL})$ & $0.002(\mathrm{LH})$ & $0.009(\mathrm{LH})$ & $0.001(\mathrm{LH})$ & $0.187(\mathrm{HH})$ \\
\hline
\end{tabular}

Note: These estimates are based on specification 1 of Table 2. Unobserved heterogeneity is defined as a discrete distribution with two mass points for the unobserved term in each transition. The second mass point is defined as the deviation from the first. Four different individual types are distinguished: 1) fast parity achievers (HH), who are fast in achieving both parities; 2) slow parity achievers (LL), who are slow in achieving both parities; 3 ) slow 1 st parity achievers (LH), who are relatively slow in achieving the first parity but faster in achieving the second one; and 4) slow 2nd parity achievers (HL), who are relatively fast in achieving the first parity but slower in achieving the second. 
Table 4. Effect of a 5-year delay in motherhood on the probability of having a second birth within 5 years from the first.

\begin{tabular}{|c|c|c|}
\hline & $\begin{array}{c}\text { Never } \\
\text { employed }\end{array}$ & $\begin{array}{l}\text { Has been } \\
\text { employed }\end{array}$ \\
\hline UK & 0.096 & -0.034 \\
\hline Ireland & -0.106 & 0.024 \\
\hline Denmark & - & 0.192 \\
\hline Belgium & 0.031 & 0.021 \\
\hline Germany & 0.005 & 0.012 \\
\hline France & -0.089 & 0.119 \\
\hline Spain & -0.055 & -0.019 \\
\hline Portugal & -0.032 & -0.006 \\
\hline Italy & -0.071 & -0.003 \\
\hline Greece & -0.115 & -0.029 \\
\hline \multicolumn{3}{|c|}{$\begin{array}{l}\text { Note: These estimates are based on specification } 2 \text { of Table } 2 \text {. This table shows the } \\
\text { change in the predicted probability of having the second child within } 5 \text { years of the } \\
\text { first one induced by an increase in the age at motherhood from } 25 \text { to } 30 \text {. Positive } \\
\text { differences represent catch up effects and negative ones postponement effects. The } \\
\text { effect on fertility is computed at country specific sample mean values for the other } \\
\text { regressors. }\end{array}$} \\
\hline
\end{tabular}


Table 5. Pooled-country sample analysis.

\begin{tabular}{lccccccc}
\hline \hline & $\begin{array}{c}(1) \\
\text { North }\end{array}$ & $\begin{array}{c}(2) \\
\text { Part-Time }\end{array}$ & $\begin{array}{c}(3) \\
\text { Maternal } \\
\text { leave }\end{array}$ & $\begin{array}{c}(4) \\
\text { Child care }\end{array}$ & $\begin{array}{c}(5) \\
\text { Wages }\end{array}$ & $\begin{array}{c}(6) \\
\text { Unemployment } \\
\text { Rate }\end{array}$ & $\begin{array}{c}(7) \\
\text { Religion }\end{array}$ \\
\hline Duration to Second Birth & & & & & & & \\
Age at First Birth & -0.041 & -0.040 & -0.039 & -0.034 & -0.035 & -0.036 & -0.033 \\
& $(0.006)$ & $(0.006)$ & $(0.006)$ & $(0.006)$ & $(0.006)$ & $(0.006)$ & $(0.006)$ \\
Main Effect & 0.578 & 0.051 & 0.012 & 1.050 & 0.642 & -0.012 & -0.789 \\
& $(0.054)$ & $(0.005)$ & $(0.006)$ & $(0.141)$ & $(0.096)$ & $(0.005)$ & $(0.079)$ \\
Age at First Birth* Main Effect & 0.0283199 & 0.002 & 0.002 & 0.069 & 0.064 & 0.001 & -0.032 \\
& $(0.009)$ & $(0.001)$ & $(0.001)$ & $(0.022)$ & $(0.014)$ & $(0.001)$ & $(0.013)$ \\
\hline
\end{tabular}

Notes. The table reports the coefficient estimates for the pooled-country analysis with standard errors in parentheses.

North includes: Denmark, Belgium, France, Germany, U.K.

Part-time: Share of Part-time Employment as Percent of Total Employment for all Persons, 1976 - 2006. Source: CESifo DICE.

Maternal leave: maternity/parental leave duration (in weeks), available since 1970. Source: Gauthier, A.H., Bortnik, A. (2001). Comparative

Maternity, Parental, and Childcare Database, Version 2 (University of Calgary). On-line: http://soci.ucalgary.ca/fypp/home/family-policy/databases Child care: Public spending on childcare, percent of GDP (2005). Source: OECD Family Database.

Wages: Hourly female wages based on the annual labor earnings from ECHP (1994-2001) in Euros at 1994 prices.

Unemployment rate: unemployment rates, available since 1960, Source: OECD national labour force statistics, accessed April 2010.

Religion: the fraction of Christian Catholic or Christian Ortodox population in 2000. Source: Religion Adherence Data. On-line:

http://www.economics.harvard.edu/faculty/barro/files/religion adherence data.xls, accessed April 2010. 


\section{APPENDIX A}

Table A1. Means of main variables.

\begin{tabular}{|c|c|c|c|c|c|c|c|c|c|c|}
\hline & Belgium & Denmark & France & Germany & Greece & Ireland & Italy & Portugal & Spain & UK \\
\hline Age & 32.29 & 32.31 & 32.56 & 30.83 & 32.41 & 32.49 & 32.17 & 32.35 & 32.18 & 32.08 \\
\hline Married & 0.70 & 0.49 & 0.59 & 0.66 & 0.81 & 0.75 & 0.77 & 0.79 & 0.74 & 0.61 \\
\hline Divorced & 0.17 & 0.14 & 0.12 & 0.15 & 0.06 & 0.06 & 0.05 & 0.10 & 0.08 & 0.19 \\
\hline Number of Children & 1.42 & 1.23 & 1.58 & 1.08 & 1.40 & 1.71 & 1.05 & 1.40 & 1.13 & 1.33 \\
\hline High Education & 0.43 & 0.52 & 0.24 & 0.36 & 0.32 & 0.16 & 0.12 & 0.10 & 0.30 & 0.36 \\
\hline Medium Education & 0.33 & 0.44 & 0.42 & 0.45 & 0.30 & 0.49 & 0.44 & 0.17 & 0.21 & 0.15 \\
\hline Low Education & 0.22 & 0.04 & 0.32 & 0.19 & 0.37 & 0.35 & 0.44 & 0.73 & 0.49 & 0.48 \\
\hline Mean Duration to 1st Birth & 11.64 & 12.36 & 10.96 & 11.68 & 10.41 & 11.61 & 12.74 & 10.13 & 12.17 & 12.44 \\
\hline Mean Duration to 2nd Birth & 6.05 & 5.94 & 6.26 & 6.50 & 5.47 & 4.59 & 6.56 & 7.65 & 6.49 & 5.49 \\
\hline Number of Observations & 718 & 537 & 810 & 737 & 1232 & 880 & 1801 & 1018 & 1689 & 898 \\
\hline
\end{tabular}

Note: The sample includes women aged 28-37 at the first observed wave from ECHP (1994-2001). 
Table A2. Transition to first and second birth under the independence assumption.

\begin{tabular}{|c|c|c|c|c|c|c|c|c|c|c|}
\hline & Belgium & Denmark & France & Germany & Greece & Ireland & Italy & Portugal & Spain & UK \\
\hline \multicolumn{11}{|l|}{ Duration to First Birth } \\
\hline \multirow[t]{2}{*}{ Student } & -0.790 & -0.576 & -1.484 & -0.786 & -0.506 & -0.619 & -0.392 & -0.441 & -0.406 & -0.151 \\
\hline & $(0.252)$ & $(0.182)$ & $(0.433)$ & $(0.181)$ & $(0.217)$ & $(0.297)$ & $(0.162)$ & $(0.194)$ & $(0.153)$ & $(0.257)$ \\
\hline \multirow[t]{2}{*}{ High Education } & -0.151 & 0.149 & -0.377 & 0.668 & -0.352 & -0.150 & -0.268 & -0.451 & -0.383 & -0.366 \\
\hline & $(0.134)$ & $(0.281)$ & $(0.142)$ & $(0.145)$ & $(0.113)$ & $(0.172)$ & $(0.124)$ & $(0.165)$ & $(0.093)$ & $(0.108)$ \\
\hline \multirow[t]{2}{*}{ Medium Education } & -0.088 & 0.450 & -0.353 & 0.331 & -0.345 & -0.249 & -0.319 & -0.174 & -0.233 & -0.291 \\
\hline & $(0.123)$ & $(0.282)$ & $(0.103)$ & $(0.132)$ & $(0.100)$ & $(0.110)$ & $(0.073)$ & $(0.120)$ & $(0.088)$ & $(0.125)$ \\
\hline \multirow[t]{2}{*}{ Married } & 2.000 & 1.542 & 1.960 & 2.236 & 4.181 & 2.942 & 3.510 & 3.270 & 3.470 & 1.756 \\
\hline & $(0.109)$ & $(0.119)$ & $(0.094)$ & $(0.105)$ & $(0.138)$ & $(0.122)$ & $(0.094)$ & $(0.111)$ & $(0.098)$ & $(0.095)$ \\
\hline \multirow[t]{2}{*}{ Divorced } & 0.799 & 0.285 & 1.142 & 0.632 & 1.788 & 1.225 & 0.479 & 1.505 & 1.638 & 0.888 \\
\hline & $(0.132)$ & $(0.153)$ & $(0.138)$ & $(0.133)$ & $(0.197)$ & $(0.205)$ & $(0.147)$ & $(0.150)$ & $(0.135)$ & $(0.107)$ \\
\hline \multirow[t]{2}{*}{ Has Been Employed } & -1.513 & - & -1.381 & 0.036 & -0.062 & -1.243 & -0.297 & -0.259 & -0.387 & -1.601 \\
\hline & $(0.254)$ & - & $(0.231)$ & $(0.169)$ & $(0.119)$ & $(0.404)$ & $(0.115)$ & $(0.149)$ & $(0.143)$ & $(0.287)$ \\
\hline \multirow[t]{2}{*}{ Years since First Job } & 2.131 & 2.025 & 2.573 & 1.146 & 0.637 & 2.509 & 0.506 & -0.085 & 0.823 & 2.756 \\
\hline & $(0.499)$ & $(0.460)$ & $(0.449)$ & $(0.378)$ & $(0.263)$ & $(0.649)$ & $(0.220)$ & $(0.252)$ & $(0.224)$ & $(0.415)$ \\
\hline \multirow[t]{2}{*}{ Years since First $\mathrm{Job}^{\wedge} 2$} & -1.312 & -1.021 & -1.492 & -0.505 & -0.338 & -0.871 & -0.269 & 0.093 & -0.456 & -1.229 \\
\hline & $(0.258)$ & $(0.243)$ & $(0.246)$ & $(0.225)$ & $(0.160)$ & $(0.293)$ & $(0.114)$ & $(0.140)$ & $(0.109)$ & $(0.187)$ \\
\hline \multicolumn{11}{|l|}{ Duration to Second Birth } \\
\hline \multirow[t]{2}{*}{ Age at First Birth } & 0.016 & 0.021 & 0.028 & -0.008 & -0.051 & -0.041 & -0.030 & -0.063 & -0.045 & -0.017 \\
\hline & $(0.024)$ & $(0.027)$ & $(0.024)$ & $(0.022)$ & $(0.014)$ & $(0.031)$ & $(0.013)$ & $(0.017)$ & $(0.014)$ & $(0.023)$ \\
\hline \multirow[t]{2}{*}{ High Education } & 0.380 & 1.139 & 0.115 & -0.108 & -0.422 & 0.410 & 0.261 & 0.666 & 0.084 & 0.084 \\
\hline & $(0.163)$ & $(0.441)$ & $(0.168)$ & $(0.177)$ & $(0.120)$ & $(0.217)$ & $(0.171)$ & $(0.194)$ & $(0.113)$ & $(0.136)$ \\
\hline \multirow[t]{2}{*}{ Medium Education } & 0.135 & 1.141 & -0.021 & -0.066 & -0.178 & 0.042 & 0.070 & 0.178 & -0.020 & 0.169 \\
\hline & $(0.146)$ & $(0.438)$ & $(0.118)$ & $(0.165)$ & $(0.102)$ & $(0.128)$ & $(0.087)$ & $(0.147)$ & $(0.100)$ & $(0.151)$ \\
\hline \multirow[t]{2}{*}{ Married } & 0.302 & 0.554 & 0.663 & 0.637 & 1.045 & 1.234 & 1.120 & 0.268 & 0.763 & 0.988 \\
\hline & $(0.167)$ & $(0.139)$ & $(0.123)$ & $(0.183)$ & $(0.261)$ & $(0.178)$ & $(0.211)$ & $(0.176)$ & $(0.165)$ & $(0.138)$ \\
\hline \multirow[t]{2}{*}{ Divorced } & -0.262 & -0.059 & 0.022 & -0.166 & -0.367 & 0.335 & 0.023 & 0.002 & 0.074 & 0.170 \\
\hline & $(0.189)$ & $(0.195)$ & $(0.172)$ & $(0.193)$ & $(0.251)$ & $(0.220)$ & $(0.215)$ & $(0.185)$ & $(0.170)$ & $(0.144)$ \\
\hline \multirow[t]{2}{*}{ Has Been Employed } & -0.192 & - & -0.744 & 0.354 & 0.301 & -0.529 & -0.430 & -0.490 & 0.122 & -0.656 \\
\hline & $(0.333)$ & - & $(0.352)$ & $(0.253)$ & $(0.147)$ & $(0.620)$ & $(0.178)$ & $(0.188)$ & $(0.192)$ & $(0.404)$ \\
\hline \multirow[t]{2}{*}{ Years since First Job } & 0.570 & 1.395 & 0.884 & 0.284 & -0.238 & 0.660 & 0.155 & -0.316 & -0.025 & 0.882 \\
\hline & $(0.446)$ & $(0.607)$ & $(0.478)$ & $(0.418)$ & $(0.251)$ & $(0.636)$ & $(0.264)$ & $(0.257)$ & $(0.232)$ & $(0.452)$ \\
\hline \multirow[t]{2}{*}{ Years since First Job`2 } & -0.529 & -0.631 & -0.627 & -0.208 & 0.067 & -0.241 & -0.146 & 0.097 & 0.003 & -0.452 \\
\hline & $(0.201)$ & $(0.232)$ & $(0.190)$ & $(0.201)$ & $(0.130)$ & $(0.213)$ & $(0.109)$ & $(0.107)$ & $(0.090)$ & $(0.170)$ \\
\hline \multirow[t]{2}{*}{ First Child a Boy } & -0.016 & -0.043 & -0.018 & 0.170 & -0.020 & -0.139 & 0.153 & 0.105 & 0.102 & 0.196 \\
\hline & $(0.110)$ & $(0.130)$ & $(0.100)$ & $(0.120)$ & $(0.083)$ & $(0.102)$ & $(0.076)$ & $(0.092)$ & $(0.076)$ & $(0.102)$ \\
\hline
\end{tabular}

Note: The table reports coefficient estimates with standard errors in parentheses from the transition to first and second birth estimated for each country separately. The model is estimated assuming no unobserved heterogeneity. Other controls include year dummies to capture time-varying policies or macro-economics factors and duration dependence dummies. For Denmark, the coefficient on the variable has been employed cannot be estimated due to low variation as most of women have been employed at least once in their lifetime. 
Table A3. Transition to first and second birth with correlated unobserved heterogeneity.

\begin{tabular}{|c|c|c|c|c|c|c|c|c|c|c|}
\hline & Belgium & Denmark & France & Germany & Greece & Ireland & Italy & Portugal & Spain & UK \\
\hline \multicolumn{11}{|l|}{ Duration to First Birth } \\
\hline Student & $\begin{array}{c}-0.789 \\
(0.256)\end{array}$ & $\begin{array}{c}-0.553 \\
(0.187)\end{array}$ & $\begin{array}{c}-1.362 \\
(0.437)\end{array}$ & $\begin{array}{l}-0.816 \\
(0.188)\end{array}$ & $\begin{array}{c}-0.394 \\
(0.224)\end{array}$ & $\begin{array}{c}-0.585 \\
(0.304)\end{array}$ & $\begin{array}{l}-0.333 \\
(0.167)\end{array}$ & $\begin{array}{c}-0.349 \\
(0.205)\end{array}$ & $\begin{array}{c}-0.403 \\
(0.159)\end{array}$ & $\begin{array}{l}-0.085 \\
(0.262)\end{array}$ \\
\hline High Education & $\begin{array}{c}-0.234 \\
(0.162)\end{array}$ & $\begin{array}{c}0.177 \\
(0.316)\end{array}$ & $\begin{array}{c}-0.560 \\
(0.168)\end{array}$ & $\begin{array}{c}0.626 \\
(0.174)\end{array}$ & $\begin{array}{c}-0.532 \\
(0.129)\end{array}$ & $\begin{array}{c}-0.344 \\
(0.190)\end{array}$ & $\begin{array}{c}-0.560 \\
(0.141)\end{array}$ & $\begin{array}{c}-0.703 \\
(0.183)\end{array}$ & $\begin{array}{c}-0.518 \\
(0.104)\end{array}$ & $\begin{array}{l}-0.335 \\
(0.132)\end{array}$ \\
\hline Medium Education & $\begin{array}{c}-0.044 \\
(0.147)\end{array}$ & $\begin{array}{c}0.461 \\
(0.314)\end{array}$ & $\begin{array}{l}-0.466 \\
(0.122)\end{array}$ & $\begin{array}{c}0.172 \\
(0.159)\end{array}$ & $\begin{array}{l}-0.419 \\
(0.112)\end{array}$ & $\begin{array}{c}-0.380 \\
(0.126)\end{array}$ & $\begin{array}{c}-0.474 \\
(0.083)\end{array}$ & $\begin{array}{c}-0.415 \\
(0.133)\end{array}$ & $\begin{array}{c}-0.233 \\
(0.097)\end{array}$ & $\begin{array}{l}-0.256 \\
(0.147)\end{array}$ \\
\hline Married & $\begin{array}{c}2.298 \\
(0.124)\end{array}$ & $\begin{array}{c}1.669 \\
(0.145)\end{array}$ & $\begin{array}{c}2.198 \\
(0.107)\end{array}$ & $\begin{array}{c}2.617 \\
(0.124)\end{array}$ & $\begin{array}{c}4.382 \\
(0.146)\end{array}$ & $\begin{array}{c}3.088 \\
(0.130)\end{array}$ & $\begin{array}{c}3.739 \\
(0.101)\end{array}$ & $\begin{array}{c}3.561 \\
(0.122)\end{array}$ & $\begin{array}{c}3.729 \\
(0.112)\end{array}$ & $\begin{array}{c}1.978 \\
(0.116)\end{array}$ \\
\hline Divorced & $\begin{array}{c}1.154 \\
(0.170)\end{array}$ & $\begin{array}{c}0.434 \\
(0.181)\end{array}$ & $\begin{array}{c}1.401 \\
(0.183)\end{array}$ & $\begin{array}{c}0.603 \\
(0.156)\end{array}$ & $\begin{array}{c}1.992 \\
(0.214)\end{array}$ & $\begin{array}{c}1.716 \\
(0.286)\end{array}$ & $\begin{array}{c}1.417 \\
(0.198)\end{array}$ & $\begin{array}{c}1.929 \\
(0.185)\end{array}$ & $\begin{array}{c}2.153 \\
(0.179)\end{array}$ & $\begin{array}{c}1.085 \\
(0.161)\end{array}$ \\
\hline Has Been Employed & $\begin{array}{c}-1.478 \\
(0.274)\end{array}$ & $\begin{array}{l}- \\
-\end{array}$ & $\begin{array}{l}-1.401 \\
(0.244)\end{array}$ & $\begin{array}{c}-0.164 \\
(0.188)\end{array}$ & $\begin{array}{c}-0.042 \\
(0.129)\end{array}$ & $\begin{array}{c}-1.124 \\
(0.429)\end{array}$ & $\begin{array}{c}-0.267 \\
(0.123)\end{array}$ & $\begin{array}{c}-0.255 \\
(0.159)\end{array}$ & $\begin{array}{c}-0.381 \\
(0.154)\end{array}$ & $\begin{array}{c}-1.682 \\
(0.387)\end{array}$ \\
\hline Years since First Job & $\begin{array}{c}2.080 \\
(0.474)\end{array}$ & $\begin{array}{c}2.002 \\
(0.484)\end{array}$ & $\begin{array}{c}2.429 \\
(0.471)\end{array}$ & $\begin{array}{c}1.279 \\
(0.415)\end{array}$ & $\begin{array}{c}0.460 \\
(0.283)\end{array}$ & $\begin{array}{c}2.136 \\
(0.689)\end{array}$ & $\begin{array}{c}0.252 \\
(0.253)\end{array}$ & $\begin{array}{c}-0.282 \\
(0.266)\end{array}$ & $\begin{array}{c}0.657 \\
(0.263)\end{array}$ & $\begin{array}{c}2.640 \\
(0.450)\end{array}$ \\
\hline Years since First Job`2 & $\begin{array}{l}-1.155 \\
(0.288)\end{array}$ & $\begin{array}{l}-0.957 \\
(0.257)\end{array}$ & $\begin{array}{l}-1.203 \\
(0.267)\end{array}$ & $\begin{array}{c}-0.454 \\
(0.258)\end{array}$ & $\begin{array}{l}-0.098 \\
(0.185)\end{array}$ & $\begin{array}{l}-0.625 \\
(0.319)\end{array}$ & $\begin{array}{c}-0.142 \\
(0.144)\end{array}$ & $\begin{array}{c}0.283 \\
(0.150)\end{array}$ & $\begin{array}{l}-0.327 \\
(0.146)\end{array}$ & $\begin{array}{l}-1.098 \\
(0.213)\end{array}$ \\
\hline \multicolumn{11}{|l|}{ Duration to Second Birth } \\
\hline Age at First Birth & $\begin{array}{c}0.048 \\
(0.039)\end{array}$ & $\begin{array}{c}0.133 \\
(0.040)\end{array}$ & $\begin{array}{c}0.057 \\
(0.030)\end{array}$ & $\begin{array}{c}0.006 \\
(0.027)\end{array}$ & $\begin{array}{c}-0.037 \\
(0.018)\end{array}$ & $\begin{array}{c}-0.039 \\
(0.034)\end{array}$ & $\begin{array}{c}-0.021 \\
(0.017)\end{array}$ & $\begin{array}{c}-0.043 \\
(0.022)\end{array}$ & $\begin{array}{c}-0.046 \\
(0.017)\end{array}$ & $\begin{array}{c}-0.016 \\
(0.025)\end{array}$ \\
\hline High Education & $\begin{array}{c}0.599 \\
(0.238)\end{array}$ & $\begin{array}{c}1.624 \\
(0.484)\end{array}$ & $\begin{array}{c}0.033 \\
(0.197)\end{array}$ & $\begin{array}{c}0.082 \\
(0.244)\end{array}$ & $\begin{array}{l}-0.657 \\
(0.142)\end{array}$ & $\begin{array}{c}0.381 \\
(0.239)\end{array}$ & $\begin{array}{c}0.258 \\
(0.217)\end{array}$ & $\begin{array}{c}0.670 \\
(0.280)\end{array}$ & $\begin{array}{c}0.141 \\
(0.144)\end{array}$ & $\begin{array}{c}0.102 \\
(0.151)\end{array}$ \\
\hline Medium Education & $\begin{array}{c}0.242 \\
(0.191)\end{array}$ & $\begin{array}{c}1.591 \\
(0.482)\end{array}$ & $\begin{array}{l}-0.036 \\
(0.137)\end{array}$ & $\begin{array}{c}-0.055 \\
(0.208)\end{array}$ & $\begin{array}{l}-0.317 \\
(0.120)\end{array}$ & $\begin{array}{c}-0.018 \\
(0.152)\end{array}$ & $\begin{array}{c}0.081 \\
(0.111)\end{array}$ & $\begin{array}{c}0.073 \\
(0.194)\end{array}$ & $\begin{array}{c}0.030 \\
(0.127)\end{array}$ & $\begin{array}{c}0.179 \\
(0.170)\end{array}$ \\
\hline Married & $\begin{array}{c}0.414 \\
(0.226)\end{array}$ & $\begin{array}{c}0.887 \\
(0.165)\end{array}$ & $\begin{array}{c}0.841 \\
(0.150)\end{array}$ & $\begin{array}{c}0.697 \\
(0.233)\end{array}$ & $\begin{array}{c}1.280 \\
(0.293)\end{array}$ & $\begin{array}{c}1.403 \\
(0.237)\end{array}$ & $\begin{array}{c}1.371 \\
(0.255)\end{array}$ & $\begin{array}{c}0.601 \\
(0.235)\end{array}$ & $\begin{array}{c}1.033 \\
(0.205)\end{array}$ & $\begin{array}{c}1.085 \\
(0.168)\end{array}$ \\
\hline Divorced & $\begin{array}{c}-0.206 \\
(0.262)\end{array}$ & $\begin{array}{c}0.161 \\
(0.238)\end{array}$ & $\begin{array}{c}0.152 \\
(0.199)\end{array}$ & $\begin{array}{c}-0.334 \\
(0.258)\end{array}$ & $\begin{array}{c}-0.402 \\
(0.292)\end{array}$ & $\begin{array}{c}0.568 \\
(0.280)\end{array}$ & $\begin{array}{c}0.145 \\
(0.271)\end{array}$ & $\begin{array}{c}0.333 \\
(0.276)\end{array}$ & $\begin{array}{c}0.199 \\
(0.219)\end{array}$ & $\begin{array}{c}0.184 \\
(0.163)\end{array}$ \\
\hline Has Been Employed & $\begin{array}{c}0.135 \\
(0.421)\end{array}$ & $\begin{array}{l}- \\
-\end{array}$ & $\begin{array}{c}-0.957 \\
(0.395)\end{array}$ & $\begin{array}{c}0.508 \\
(0.309)\end{array}$ & $\begin{array}{c}0.390 \\
(0.163)\end{array}$ & $\begin{array}{l}-0.545 \\
(0.664)\end{array}$ & $\begin{array}{c}-0.592 \\
(0.227)\end{array}$ & $\begin{array}{c}-0.844 \\
(0.222)\end{array}$ & $\begin{array}{c}0.103 \\
(0.228)\end{array}$ & $\begin{array}{c}-0.693 \\
(0.446)\end{array}$ \\
\hline Years since First Job & $\begin{array}{c}0.640 \\
(0.534)\end{array}$ & $\begin{array}{c}0.472 \\
(0.792)\end{array}$ & $\begin{array}{c}0.813 \\
(0.518)\end{array}$ & $\begin{array}{c}0.241 \\
(0.502)\end{array}$ & $\begin{array}{c}-0.250 \\
(0.297)\end{array}$ & $\begin{array}{c}0.596 \\
(0.681)\end{array}$ & $\begin{array}{c}0.321 \\
(0.328)\end{array}$ & $\begin{array}{c}-0.114 \\
(0.306)\end{array}$ & $\begin{array}{c}-0.044 \\
(0.275)\end{array}$ & $\begin{array}{c}0.931 \\
(0.498)\end{array}$ \\
\hline Years since First Job^2 & $\begin{array}{c}-0.624 \\
(0.234)\end{array}$ & $\begin{array}{c}-0.397 \\
(0.353)\end{array}$ & $\begin{array}{c}-0.642 \\
(0.207)\end{array}$ & $\begin{array}{l}-0.143 \\
(0.259)\end{array}$ & $\begin{array}{c}0.093 \\
(0.170)\end{array}$ & $\begin{array}{c}-0.176 \\
(0.234)\end{array}$ & $\begin{array}{c}-0.229 \\
(0.136)\end{array}$ & $\begin{array}{c}-0.034 \\
(0.142)\end{array}$ & $\begin{array}{c}0.024 \\
(0.111)\end{array}$ & $\begin{array}{c}-0.476 \\
(0.186)\end{array}$ \\
\hline First Child a Boy & $\begin{array}{c}0.012 \\
(0.149)\end{array}$ & $\begin{array}{c}-0.063 \\
(0.156)\end{array}$ & $\begin{array}{c}0.020 \\
(0.116)\end{array}$ & $\begin{array}{c}0.143 \\
(0.164)\end{array}$ & $\begin{array}{c}0.011 \\
(0.097)\end{array}$ & $\begin{array}{c}-0.118 \\
(0.110)\end{array}$ & $\begin{array}{c}0.210 \\
(0.097)\end{array}$ & $\begin{array}{c}0.158 \\
(0.119)\end{array}$ & $\begin{array}{c}0.141 \\
(0.097)\end{array}$ & $\begin{array}{c}0.211 \\
(0.113)\end{array}$ \\
\hline
\end{tabular}

Note: The table reports coefficient estimates with standard errors in parentheses. These estimates are based on specification 1 of Table 2 . 